\title{
In reply: Personal protective equipment during the COVID-19 pandemic (Letters \#1 and \#2)
}

\author{
Laura V. Duggan, MD, FRCPC (1) - Shannon L. Lockhart, MD, FRCPC · Hilary P. Grocott, MD, FRCPC
}

Received: 30 July 2020/Accepted: 30 July 2020/Published online: 11 August 2020

(C) Canadian Anesthesiologists' Society 2020

\section{To the Editor,}

We would like to thank Dr. Shorten ${ }^{1}$ and Dr. Hung et $a l^{2}$ for their interest in our article. ${ }^{3}$ Both authors have focused (and rightly so) on the donning and doffing processes of personal protective equipment (PPE). We agree with both commentaries that those PPE procedural skills should be acquired during simulation sessions prior to their use during patient care. We also agree that, in our climate of current and potential future PPE shortages, sharing PPE in simulation to preserve supply presents a potential nidus for transmission. Given this, achieving donning and doffing proficiency during the pandemic certainly presents challenges. Its simulation does not have to be performed with the specific PPE items and in fact, this is likely impossible to achieve as supply chains mandate substitutions of various PPE items at various times (e.g., impervious gowns or N95 masks). In addition, the cognitive rehearsal and emphasis of the key concepts of PPE donning and doffing using well-made cognitive aids

It is related to letter \#1 20-00445 and letter \#2 20-00439.

L. V. Duggan, MD, FRCPC ( $\square)$

Department of Anesthesiology and Pain Medicine, University of Ottawa, Ottawa, ON, Canada

e-mail: laduggan@toh.ca

S. L. Lockhart, MD, FRCPC

Department of Anesthesiology, Pharmacology and Therapeutics,

University of British Columbia, Vancouver, BC, Canada

H. P. Grocott, MD, FRCPC

Department of Anesthesiology, Perioperative Medicine,

University of Manitoba, Winnipeg, MB, Canada and visual demonstrations (e.g., videos, posters, etc.) in the presence of a trained observer may offer a stopgap until PPE substitutes are re-supplied.

The most important lesson to be learned during simulation sessions relates to the key concepts and proficiency of the donning and doffing procedures. This depends on direct observation and real-time feedback from a trained observer (i.e., a "PPE coach"). Compulsory steps in donning and doffing should include the presence of a PPE coach every time PPE is used in a clinical situation. Airway management is a high-risk procedure that can expose multiple healthcare workers (HCWs) to droplets and aerosols. Given the potential for $\mathrm{HCW}$ contamination and infection, both donning and doffing are often performed in a high-stress cognitive state; the HCW cannot rely upon recall or self-monitoring to perform these procedures correctly. Indeed, doing so has been shown to be ineffective and places others at risk of contamination. Donning and doffing takes time, and a PPE coach who reads aloud the donning and doffing steps every time the procedures are performed has been shown to decrease PPE protocol breaches. ${ }^{4}$

Dr. Hung offers a controversial suggestion that a procedural gown may not need to be used during airway management for COVID-19 patients if the airway manager is able to change their hospital scrubs and shower immediately after the procedure. ${ }^{2}$ We would emphasize that gowns have not been the rate-limiting step of the PPE supply chain in Canada. Instead, the supply, distribution, and appropriate use of N95 masks or equivalent respiratory protection has been, and continues to be, threatened by an uncertain supply chain. Airway management mandates the ability to doff a highly contaminated external layer immediately and under direct supervision of a PPE coach before walking to the change room and shower facilities. 
We would caution against recommending a level of PPE that provides less protection than the Health Canada recommended standards. ${ }^{\mathrm{A}}$

Dr. Shorten has highlighted that the discipline of anesthesia has been at the forefront of competency training. We would also submit that anesthesia providers are often called upon to work more, but with less. Whether that be in the form of shortages or lack of equipment, medications, or support personnel, anesthesia providers are often encouraged to "carry on". The normalization of deviance, or a cultural acceptance of such shortages, may influence anesthesiologists to not insist on a real-time donning and doffing PPE coach, yet alone the availability of the recommended PPE standard. As hospitals in Canada begin to ramp-up surgical procedures, it is our responsibility to be role-models in $\mathrm{HCW}$ safety and advocate for ourselves and our other HCW colleagues to maintain appropriate PPE protocols. It will be a paradigm shift to view PPE protocols, including real-time coaching, as an investment in $\mathrm{HCW}$ safety and morale, ${ }^{5}$ and not simply as a threat to operating room efficiency.

Disclosures None.

Funding statement None.
Editorial responsibility This submission was handled by Dr. Philip M. Jones, Associate Editor, Canadian Journal of Anesthesia

\section{References}

1. Shorten GD. Personal protective equipment during the COVID-19 pandemic (Letter \#1). Can J Anesth 2020; DOI: https://doi.org/10. 1007/s12630-020-01784-4.

2. Hung O, Lehmann C, Coonan T, Murphy M, Stewart R. Personal protective equipment during the COVID-19 pandemic (Letter \#2). Can J Anesth 2020; DOI: https://doi.org/10.1007/s12630-02001785-3.

3. Lockhart SL, Duggan LV, Wax RS, Saad S, Grocott HP. Personal protective equipment (PPE) for both anesthesiologists and other airway managers: principles and practice during the COVID-19 pandemic. Can J Anesth 2020; DOI: https://doi.org/10.1007/ s12630-020-01673-w.

4. Verbeek JH, Rajamaki B, Ijaz S, et al. Personal protective equipment for preventing highly infectious diseases due to exposure to contaminated body fluids in healthcare staff. Cochrane Database Syst Rev 2019; DOI: https://doi.org/10.1002/ 14651858.CD011621.pub5.

5. Crosby L, Crosby E. Applying the precautionary principle to personal protective equipment (PPE) guidance during the COVID19 pandemic: did we learn the lessons of SARS? Can J Anesth 2020; DOI: https://doi.org/10.1007/s12630-020-01760-y.

Publisher's Note Springer Nature remains neutral with regard to jurisdictional claims in published maps and institutional affiliations.

A Government of Canada. Public Healthcare Agency of Canada. Infection prevention and control for coronavirus disease (COVID-19): Interim guidance for acute healthcare settings. Available from URL: https://www.canada.ca/en/public-health/services/diseases/2019novel-coronavirus-infection/health-professionals/infectionprevention-control-covid-19-second-interim-guidance.html\#a8.7 (Available April 30, 2020. Updated May 19, 2020) (accessed August 2020). 